\title{
Difficult Management of a Double-Lumen Endotracheal Tube and Difficult Ventilation during Robotic Thymectomy with Carbon Dioxide Insufflation
}

\author{
Yuki Sugiyama, ${ }^{1}$ Kunihiro Mitsuzawa, ${ }^{1}$ Yuki Yoshiyama, ${ }^{1}$ \\ Fumiko Shimizu, ${ }^{1}$ Satoshi Fuseya, ${ }^{1}$ Takashi Ichino, ${ }^{1}$ Hiroyuki Agatsuma, ${ }^{2}$ \\ Takayuki Shiina, ${ }^{2}$ Ken-ichi Ito, ${ }^{2}$ and Mikito Kawamata ${ }^{1}$ \\ ${ }^{1}$ Department of Anesthesiology and Resuscitology, Shinshu University School of Medicine, Matsumoto, Japan \\ ${ }^{2}$ Division of Breast, Endocrine and Respiratory Surgery, Department of Surgery (II), Shinshu University School of Medicine, \\ Matsumoto, Japan \\ Correspondence should be addressed to Yuki Sugiyama; ysugiyama@shinshu-u.ac.jp
}

Received 16 January 2017; Revised 2 April 2017; Accepted 11 April 2017; Published 26 April 2017

Academic Editor: Angelo Carretta

Copyright (C) 2017 Yuki Sugiyama et al. This is an open access article distributed under the Creative Commons Attribution License, which permits unrestricted use, distribution, and reproduction in any medium, provided the original work is properly cited.

Robotic surgery with carbon dioxide $\left(\mathrm{CO}_{2}\right)$ insufflation to the thorax is frequently performed to gain a better operative field of view, although its intraoperative complications have not yet been discussed in detail. We treated two patients with difficult ventilation caused by distal migration of a double-lumen endotracheal tube (DLT) during robotic thymectomy. In the first case, migration of the DLT during one-lung ventilation (OLV) occurred after $\mathrm{CO}_{2}$ insufflation to the bilateral thoraxes was started. Oxygenation rapidly deteriorated because dependent lung expansion was restricted by $\mathrm{CO}_{2}$ insufflation. In the second case, migration of the DLT during OLV occurred while $\mathrm{CO}_{2}$ insufflation to a unilateral thorax and mediastinum was performed. In both cases, once migration of the DLT during OLV occurred with $\mathrm{CO}_{2}$ insufflation, readjusting the DLT became very difficult because our manipulation of bronchofiberscopy was prevented by the robot arms located above the patient's head and because deformation of the trachea/bronchus induced by $\mathrm{CO}_{2}$ insufflation caused a poor image of the bronchofiberscopic view. Thus, during roboticassisted thoracoscopic surgery with $\mathrm{CO}_{2}$ insufflation, since there is a potential risk of difficult ventilation with a DLT and since readjustment of the DLT is very difficult, discontinuing $\mathrm{CO}_{2}$ insufflation and switching to double-lung ventilation are needed in such a situation.

\section{Introduction}

Robotic-assisted thoracoscopic surgeries have recently provided a technical advance for overcoming the many limitations of conventional thoracoscopic surgeries and have gained widespread popularity in a clinical setting [1]. Carbon dioxide $\left(\mathrm{CO}_{2}\right)$ insufflation to a unilateral thorax or bilateral thoraxes is frequently performed to gain a better operative field of view, although its intraoperative complications have not yet been discussed in detail. Here we report two cases of sudden onset of difficult ventilation due to a migrated doublelumen endotracheal tube (DLT) during robotic thymectomy. We highlight the difficulty in readjustment of the migrated DLT during robotic thymectomy with continuing $\mathrm{CO}_{2}$ insufflation.

\section{Case Presentation}

2.1. Case 1. A 40-year-old woman (height, $160 \mathrm{~cm}$; weight, $60 \mathrm{~kg}$ ) with ocular myasthenia gravis was scheduled for robotic thymectomy. Computed tomography $(\mathrm{CT})$ revealed a thymoma of $35 \mathrm{~mm}$ in diameter in the anterior mediastinum. Her trachea was not deviated and her left mainstem bronchus was $40 \mathrm{~mm}$ in length. Preoperative pulmonary function values were normal. Arterial oxygen tension $\left(\mathrm{PaO}_{2}\right)$ and carbon dioxide tension $\left(\mathrm{PaCO}_{2}\right)$ under room air were $70.4 \mathrm{mmHg}$ and $45.1 \mathrm{mmHg}$, respectively. The rest of the preoperative examination was unremarkable.

General anesthesia was induced and the trachea was intubated with a 35-French left-sided DLT (Broncho-Cath ${ }^{\circledR}$, COVIDIEN, Dublin, Ireland) under bronchofiberscopic 


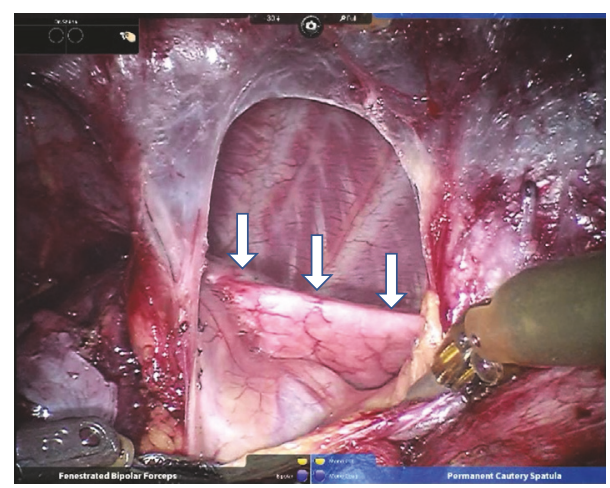

FIGURE 1: Restriction of left (dependent) lung expansion including the upper lobe of the left lung (arrow) during the inspiratory phase after an incision of the left mediastinal pleura.

guidance, confirming that the proximal bronchial cuff end was located about $5 \mathrm{~mm}$ distal from the carina. The DLT was fixed at a depth of $27 \mathrm{~cm}$ at the right angle of the mouth. Surgery was initiated in the supine position, and left onelung ventilation (OLV) was started. $\mathrm{CO}_{2}$ insufflation to the right thorax was started at $5 \mathrm{mmHg}$ and then increased to $10 \mathrm{mmHg}$. She was ventilated by pressure-controlled ventilation, volume-guaranteed mode (PCV-VG ${ }^{\circledR}, \mathrm{GE}$ Healthcare, Little Chalfont, England) at a tidal volume (TV) of $450 \mathrm{~mL}$, respiratory rate of 12 breaths/min, positive end-expiratory pressure (PEEP) of $5 \mathrm{cmH}_{2} \mathrm{O}$, and upper limit of peak inspiratory pressure (PIP) of $30 \mathrm{cmH}_{2} \mathrm{O}$, with $50 \%$ oxygen. The robot arms (da Vinci Surgical System SI ${ }^{\circledR}$, Intuitive Surgical Inc., Sunnyvale, CA, USA) were then connected to the thoracic port, and robotic thymectomy was performed.

Three hours after starting surgery, the left mediastinal pleura was incised to divide adhesions between the tumor and the left lung, and $\mathrm{CO}_{2}$ was insufflated to the bilateral thoraxes at $10 \mathrm{mmHg}$. In the operative field, the left (dependent) lung contracted rapidly and its expansion was severely interrupted (Figure 1). Although $\mathrm{SpO}_{2}$ was maintained at $98 \%$ with $50 \%$ oxygen, end-tidal $\mathrm{CO}_{2}\left(\mathrm{EtCO}_{2}\right)$ and PIP increased from 38 to $40 \mathrm{mmHg}$ and 20 to $23 \mathrm{cmH}_{2} \mathrm{O}$, respectively (Figure 2). Ten minutes after left pleural incision, TV decreased to $350 \mathrm{~mL}$ and PIP increased to $30 \mathrm{cmH}_{2} \mathrm{O}$ of the upper limit while the surgeon was pulling the left lung and dividing the adhesion between the tumor and the left lung. We attempted to assess the DLT position by bronchofiberscopy from the tracheal lumen; however, the space between the end of the tracheal lumen and tracheal wall was so narrow that we could not find the carina and bronchial cuff. The patient's cart and robot arms of da Vinci located just above her head prevented the manipulation of bronchofiberscopy. Inspired oxygen was increased to $100 \%$ and manual ventilation was started. TV reached only $250 \mathrm{~mL}$ at $40 \mathrm{cmH}_{2} \mathrm{O}$ PIP and $\mathrm{EtCO}_{2}$ increased to $60 \mathrm{mmHg}$. $\mathrm{SpO}_{2}$ simultaneously decreased to $90 \%$. Bronchofiberscopy from the bronchial lumen was avoided because hypoxia had already occurred and interrupting ventilation was unavailable. The surgeon pointed out that only the left lower lobe was ventilated, although we could not find where the bronchial cuff was located by bronchofiberscopy.
Finally, TV decreased to $150 \mathrm{~mL}$ at $40 \mathrm{cmH}_{2} \mathrm{O}$ PIP, and $\mathrm{SpO}_{2}$ decreased to $80 \%$.

At that point, $\mathrm{CO}_{2}$ insufflation was discontinued, and the robot was promptly disconnected. We immediately started double-lung ventilation. PIP decreased to $20 \mathrm{cmH}_{2} \mathrm{O}$ and TV increased to $700 \mathrm{~mL}$. The bronchofiberscopic view was improved and we found that the bronchial cuff was distally located. When we tried to readjust the position, the DLT was accidentally extubated, and then a single-lumen tube was used for intubation. We inserted a bronchial blocker $\left(\mathrm{COOPDECH}^{\circledR}\right.$ endobronchial blocker, Daiken-iki, Osaka, Japan), and left OLV was resumed. The operation was restarted in thoracoscopic surgery and completed thereafter uneventfully without conversion. Operative time was 327 minutes and blood loss was less than $100 \mathrm{~mL}$. She was extubated in the operating room and transferred to an intensive care unit (ICU). She was discharged from the ICU on postoperative day 1 and was discharged from the hospital on postoperative day 8 without complications.

2.2. Case 2. A 51-year-old man (height, $169 \mathrm{~cm}$; weight, $109 \mathrm{~kg}$ ) without symptoms was scheduled for robotic thymectomy. CT revealed a thymoma of $27 \mathrm{~mm}$ in diameter in the anterior mediastinum. His trachea was not deviated and his left mainstem bronchus was $50 \mathrm{~mm}$ in length. Preoperative pulmonary function values were normal. $\mathrm{PaO}_{2}$ and $\mathrm{PaCO}_{2}$ under room air were $73.2 \mathrm{mmHg}$ and $39.1 \mathrm{mmHg}$, respectively. He was being treated for hypertension and sleep apnea syndrome. The rest of the preoperative examination was unremarkable.

General anesthesia was induced, and the trachea was intubated with a 37-French left-sided DLT under bronchofiberscopic guidance, confirming that the proximal bronchial cuff end was located about $3 \mathrm{~mm}$ distal from the carina. The DLT was fixed at a depth of $29 \mathrm{~cm}$ at the left angle of the mouth. Surgery was initiated in a low Fowler's position. Left OLV was started and $\mathrm{CO}_{2}$ insufflation to the right thorax was started at $5 \mathrm{mmHg}$ and then increased to $10 \mathrm{mmHg}$. He was ventilated by pressure-controlled ventilation at PIP of $30 \mathrm{cmH}_{2} \mathrm{O}$, respiratory rate of 12 breaths/min, and PEEP of $10 \mathrm{cmH}_{2} \mathrm{O}$, with $100 \%$ oxygen. The robot arms were then connected to the thoracic port, and robotic thymectomy was performed. The DLT position at 20 minutes after starting surgery was the same as that at the time of intubation.

One hundred minutes after starting surgery, TV suddenly decreased from $550 \mathrm{~mL}$ to $160 \mathrm{~mL}$, and $\mathrm{SpO}_{2}$ was decreased to $82 \%$ (Figure 3). Manual ventilation was started at PIP of $35 \mathrm{cmH}_{2} \mathrm{O}$. TV reached $300 \mathrm{~mL}$ and $\mathrm{SpO}_{2}$ was increased to $88 \%$. We attempted to assess the DLT position by bronchofiberscopy; however, as in case 1, the bronchofiberscopic view was extremely poor and the robot arms prevented manual manipulation. The DLT seemed to be distally placed, but this was not convincing. Although surgeons incised the left mediastinal pleura, the situation was unchanged and they did not find a nonventilated lobe.

At that point, $\mathrm{CO}_{2}$ insufflation was discontinued and then double-lung ventilation was immediately started. PIP decreased to $28 \mathrm{cmH}_{2} \mathrm{O}$ and TV increased to $730 \mathrm{~mL}$. The bronchofiberscopic view was improved and distal migration 


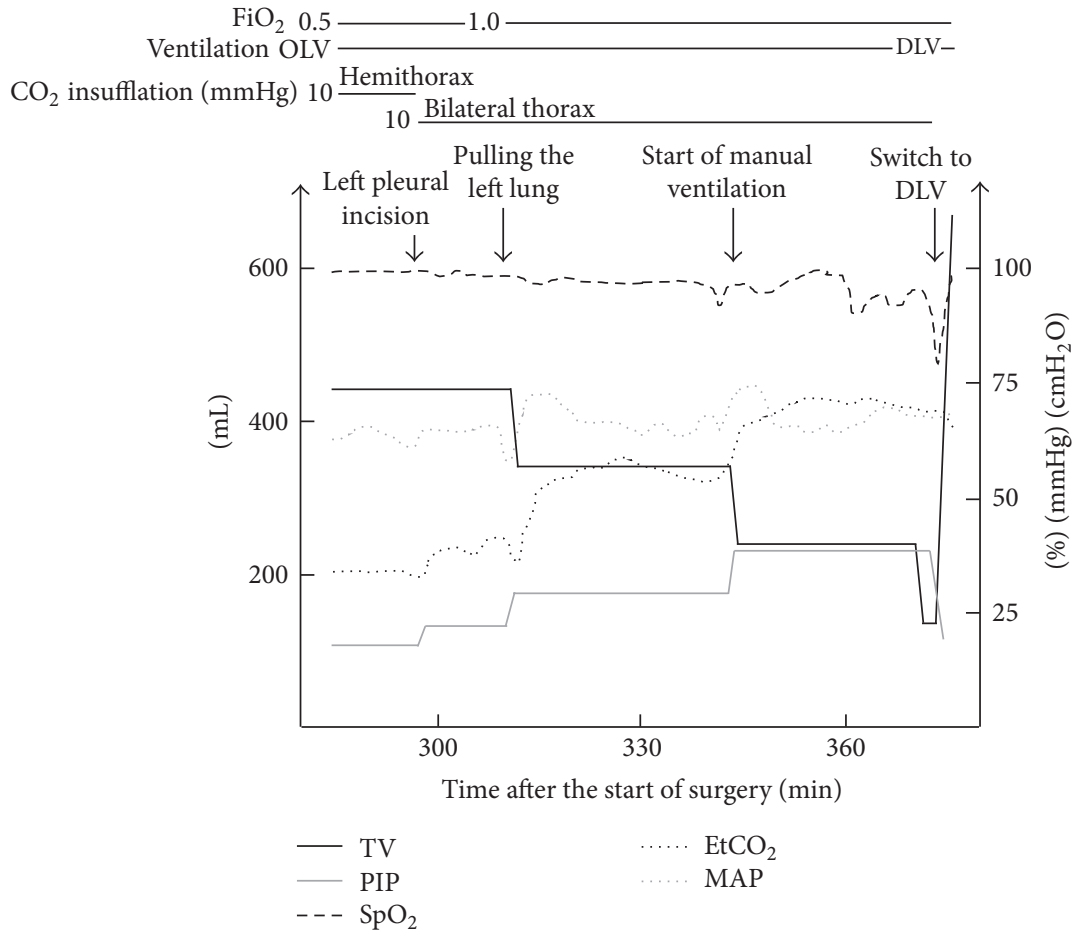

FIGURE 2: Changes of vital signs and ventilator settings in case 1. TV, tidal volume; PIP, peak inspiratory pressure; EtCO $\mathrm{C}_{2}$, end-tidal carbon dioxide; MAP, mean arterial pressure; OLV, one-lung ventilation; DLV, double-lung ventilation.
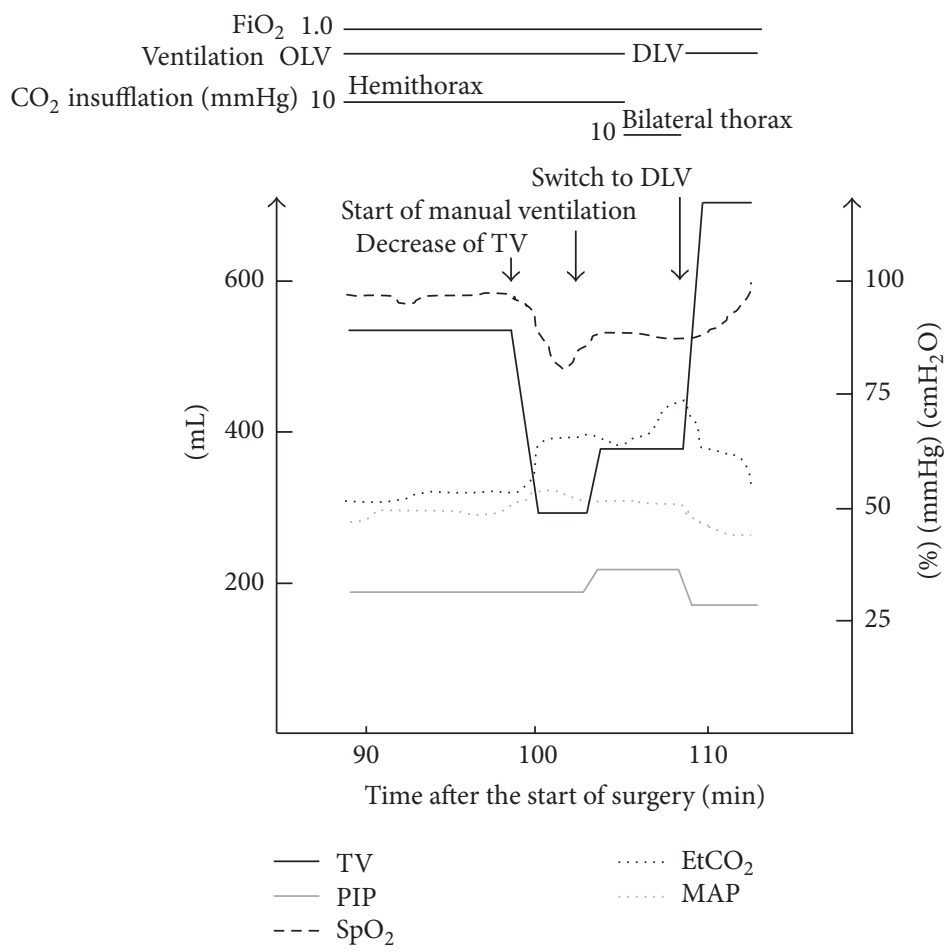

FIGURE 3: Changes of vital signs and ventilator settings in case 2. TV, tidal volume; PIP, peak inspiratory pressure; EtCO ${ }_{2}$, end-tidal carbon dioxide; MAP, mean arterial pressure; OLV, one-lung ventilation; DLV, double-lung ventilation. 
of the DLT was confirmed. The DLT was pulled out about $8 \mathrm{~mm}$ for readjustment, and then left OLV with $\mathrm{CO}_{2}$ insufflation at $5 \mathrm{mmHg}$ was resumed. Thereafter, the robotic surgery restarted and completed uneventfully without conversion. Operative time was 281 minutes and blood loss was $300 \mathrm{~mL}$. He was extubated in the operating room and discharged from the hospital on postoperative day 6 without complications.

\section{Discussion}

The introduction of robotic surgery is the most significant advance in minimally invasive surgery of this decade. Robotic-assisted thoracoscopic surgery has been tested in various thoracic surgery procedures including thymectomy $[2-5]$. The three-dimensional vision system and articulating instruments of the da Vinci Surgical Robotic System enable an intuitive "open-like" intervention with minimally invasive access $[6,7] . \mathrm{CO}_{2}$ insufflation to the thorax has been used for robotic-assisted thoracoscopic surgery to gain a better operative field of view by requests from surgeons. In robotic thymectomy, the mediastinal pleurae on both sides are intentionally incised in order to confirm the phrenic nerve location [8-12]; therefore, $\mathrm{CO}_{2}$ is sometimes insufflated to the bilateral thoraxes. The pressure of $\mathrm{CO}_{2}$ insufflation to the thorax is usually maintained at $5-15 \mathrm{mmHg}$ [9-12], although caution has been raised about difficult ventilation [11, 12].

In our cases, distal migration of the DLT occurred during $\mathrm{CO}_{2}$ insufflation to the thorax while the surgeon was manipulating the lesion site. Although migration of a DLT due to the surgical procedure is not rare in anesthetic management of OLV, we should know that $\mathrm{CO}_{2}$ insufflation itself also has a potential risk of DLT migration. It has been reported that hypoxia due to difficult ventilation caused by distal migration of a DLT occurred just after the start of $\mathrm{CO}_{2}$ insufflation during robotic thymectomy and that the migration of the DLT was thought to be caused by mediastinal shifting induced by $\mathrm{CO}_{2}$ insufflation [12]. Similarly, in our cases, distal migration of the DLT was thought to be caused not only by the surgical procedure but also by $\mathrm{CO}_{2}$ insufflation. Conceivably, a DLT during $\mathrm{CO}_{2}$ insufflation would easily migrate distally as was seen in our cases and in a previous case report [12]. We placed the DLT at a relatively shallow position in case 2 , though difficult ventilation due to distal migration of the DLT occurred. Thus, we need to pay attention to appropriate placement of the bronchial tip of the DLT not only before and after starting of $\mathrm{CO}_{2}$ insufflation but also throughout $\mathrm{CO}_{2}$ insufflation. Another possible cause of migration of a DLT is the position of the patient. Although it is unclear whether distal migration of a DLT occurs more easily in the supine positon or the lateral decubitus positon during robotic-assisted thoracoscopic surgery, the lateral decubitus position itself often causes migration of a DLT [13]. Thus, reconfirming placement of the tip of the DLT after postural change is indispensable.

$\mathrm{CO}_{2}$ insufflation to the bilateral thoraxes per se has the potential risk of hypoxia because of forced restriction of dependent lung expansion due to partial collapse of the distal trachea and bronchus. Regarding the impact of $\mathrm{CO}_{2}$ insufflation on respiratory factors, a previous study on robotic coronary artery bypass grafting showed that $\mathrm{CO}_{2}$ insufflation to bilateral thoraxes increased PIP by $5 \mathrm{mmHg}$ and $\mathrm{PaCO}_{2}$ by $15 \mathrm{mmHg}$ [14]. In case 1, increases in PIP and $\mathrm{EtCO}_{2}$ were observed at the time of insufflation to bilateral thoraxes, suggesting that thoracoscopic surgery without $\mathrm{CO}_{2}$ insufflation or open surgery should be considered in patients with respiratory complications. We also need to keep in mind that these risks of $\mathrm{CO}_{2}$ insufflation to the thorax are not only for robotic surgery but also for all thoracoscopic surgeries.

The restricted space caused by the robot system is another specific problem for anesthesiologists during robotic-assisted thoracoscopic surgery. In the simulation using da Vinci, we realized that the patient cart and robot arms of da Vinci located above the patient's head were obstacles for anesthesiologists and we adjusted the position to keep as much space as possible, although the space was not enough during the actual surgery. A new robotic system such as da Vinci $\mathrm{Xi}$, which has thin arms and instruments with a long reach, may solve this problem.

Thus, once difficult ventilation occurs during OLV with $\mathrm{CO}_{2}$ insufflation in the process of robotic-assisted thoracoscopic surgery, readjusting of the DLT is very difficult and hypoxia occurs immediately; therefore, if difficult ventilation and/or hypoxia occur, $\mathrm{CO}_{2}$ insufflation should be discontinued and double-lung ventilation should be started as soon as possible. After stabilization of vital signs and improvement of ventilation, assessment and readjustment of the DLT position should be tried. It should be easy to confirm the position of the DLT after discontinuation of $\mathrm{CO}_{2}$ insufflation because the space between the DLT and tracheal/bronchial wall would be expanded and the poor image of the bronchofiberscopic view due to deformation of the trachea/bronchus induced by $\mathrm{CO}_{2}$ insufflation would be improved as was seen in our two cases. Using a single-lumen tube with a bronchial blocker is another choice for robotic-assisted thoracoscopic surgery. This technique has already been applied to robotic mediastinal surgeries $[8,15]$.

In conclusion, we experienced two cases of difficult readjustment of a migrated DLT that resulted in difficult ventilation during robotic thymectomy. It is indispensable for surgeons and anesthesiologists to achieve a consensus that if difficult ventilation occurs, discontinuation of $\mathrm{CO}_{2}$ insufflation and restarting double-lung ventilation should be done as soon as possible.

\section{Conflicts of Interest}

The authors declare that there are no conflicts of interest regarding the publication of this paper.

\section{Authors' Contributions}

Yuki Sugiyama and Kunihiro Mitsuzawa equally contributed to this study.

\section{References}

[1] M. A. Cooper, A. Ibrahim, H. Lyu, and M. A. Makary, "Underreporting of robotic surgery complications," Journal for Healthcare Quality, 2013. 
[2] M. Argenziano, M. Katz, J. Bonatti et al., "Results of the prospective multicenter trial of robotically assisted totally endoscopic coronary artery bypass grafting," Annals of Thoracic Surgery, vol. 81, no. 5, pp. 1666-1675, 2006.

[3] F. Gharagozloo, M. Margolis, B. Tempesta, E. Strother, and F. Najam, "Robot-assisted lobectomy for early-stage lung cancer: report of 100 consecutive cases," Annals of Thoracic Surgery, vol. 88, no. 2, pp. 380-384, 2009.

[4] J. Bodner, H. Wykypiel, A. Greiner et al., "Early experience with robot-assisted surgery for mediastinal masses," Annals of Thoracic Surgery, vol. 78, no. 1, pp. 259-265, 2004.

[5] D. J. Kim, W. J. Hyung, C. Y. Lee et al., "Thoracoscopic esophagectomy for esophageal cancer: feasibility and safety of robotic assistance in the prone position," Journal of Thoracic and Cardiovascular Surgery, vol. 139, no. 1, pp. 53-59, 2010.

[6] B. Balduyck, J. M. Hendriks, P. Lauwers, R. Mercelis, P. Ten Broecke, and P. Van Schil, "Quality of life after anterior mediastinal mass resection: a prospective study comparing open with robotic-assisted thoracoscopic resection," European Journal of Cardio-thoracic Surgery, vol. 39, no. 4, pp. 543-548, 2011.

[7] Y. W. Seong, C. H. Kang, J.-W. Choi et al., "Early clinical outcomes of robot-assisted surgery for anterior mediastinal mass: its superiority over a conventional sternotomy approach evaluated by propensity score matching," European Journal of Cardio-thoracic Surgery, vol. 45, no. 3, Article ID ezt557, pp. e68-e73, 2014.

[8] R. K. Freeman, A. J. Ascioti, J. M. Van Woerkom, A. Vyverberg, and R. J. Robison, "Long-term follow-up after robotic thymectomy for nonthymomatous myasthenia gravis," Annals of Thoracic Surgery, vol. 92, no. 3, pp. 1018-1023, 2011.

[9] T. Fleck, M. Fleck, M. Müller et al., "Extended videoscopic robotic thymectomy with the da vinci telemanipulator for the treatment of myasthenia gravis: the vienna experience," Interactive Cardiovascular and Thoracic Surgery, vol. 9, no. 5, pp. 784-787, 2009.

[10] M. A. Savitt, G. Gao, A. P. Furnary, J. Swanson, H. L. Gately, and J. R. Handy, "Application of robotic-assisted techniques to the surgical evaluation and treatment of the anterior mediastinum," The Annals of Thoracic Surgery, vol. 79, no. 2, pp. 450-455, 2005.

[11] J. Campos and K. Ueda, "Update on anesthetic complications of robotic thoracic surgery," Minerva Anestesiologica, vol. 80, no. 1, pp. 83-88, 2014.

[12] R. Pandey, R. Garg, Chandralekha et al., "Robot-assisted thoracoscopic thymectomy: perianaesthetic concerns," European Journal of Anaesthesiology, vol. 27, no. 5, pp. 473-477, 2010.

[13] S. Inoue, N. Nishimine, K. Kitaguchi, H. Furuya, and S. Taniguchi, "Double lumen tube location predicts tube malposition and hypoxaemia during one lung ventilation," British Journal of Anaesthesia, vol. 92, no. 2, pp. 195-201, 2004.

[14] C. Byhahn, S. Mierdl, D. Meininger, G. Wimmer-Greinecker, G. Matheis, and K. Westphal, "Hemodynamics and gas exchange during carbon dioxide insufflation for totally endoscopic coronary artery bypass grafting," Annals of Thoracic Surgery, vol. 71, no. 5, pp. 1496-1501, 2001.

[15] S. D. Goldstein and S. C. Yang, "Assessment of robotic thymectomy using the myasthenia gravis foundation of america Guidelines," Annals of Thoracic Surgery, vol. 89, no. 4, pp. 1080-1086, 2010. 


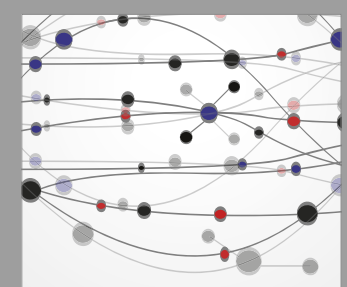

The Scientific World Journal
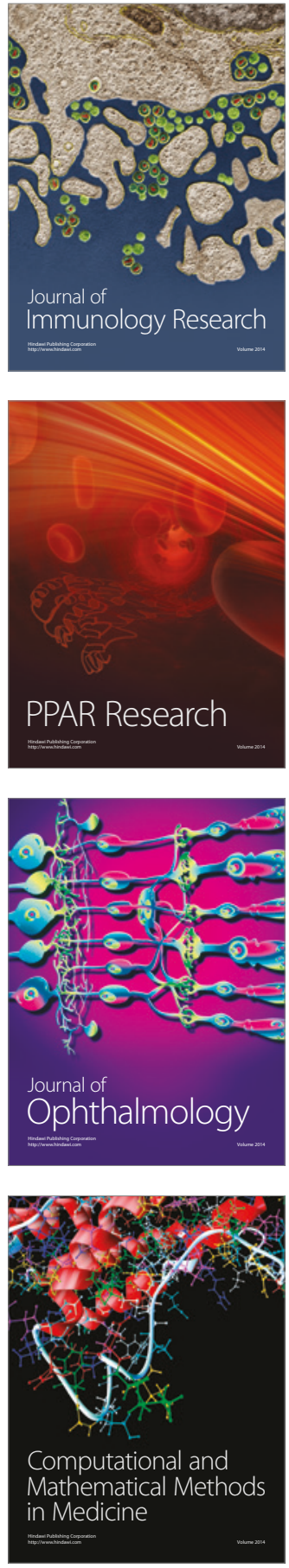

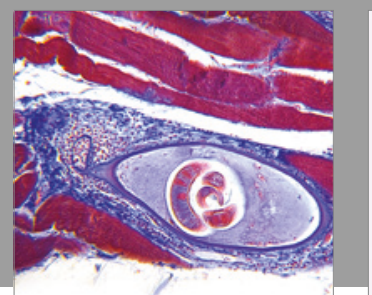

Gastroenterology Research and Practice
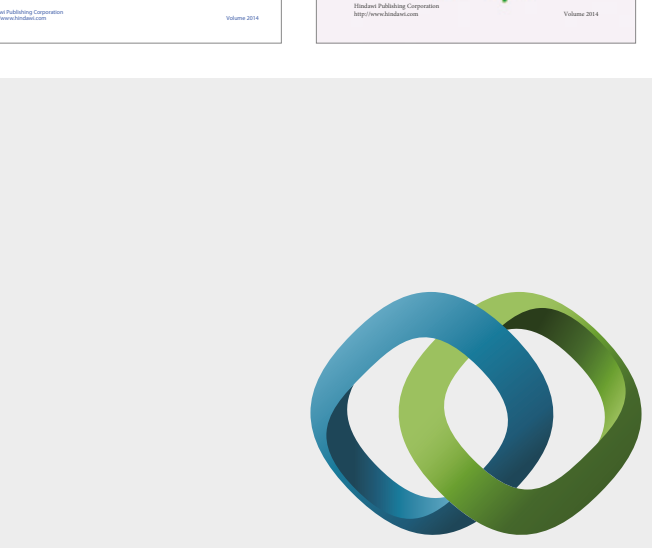

\section{Hindawi}

Submit your manuscripts at

https://www.hindawi.com
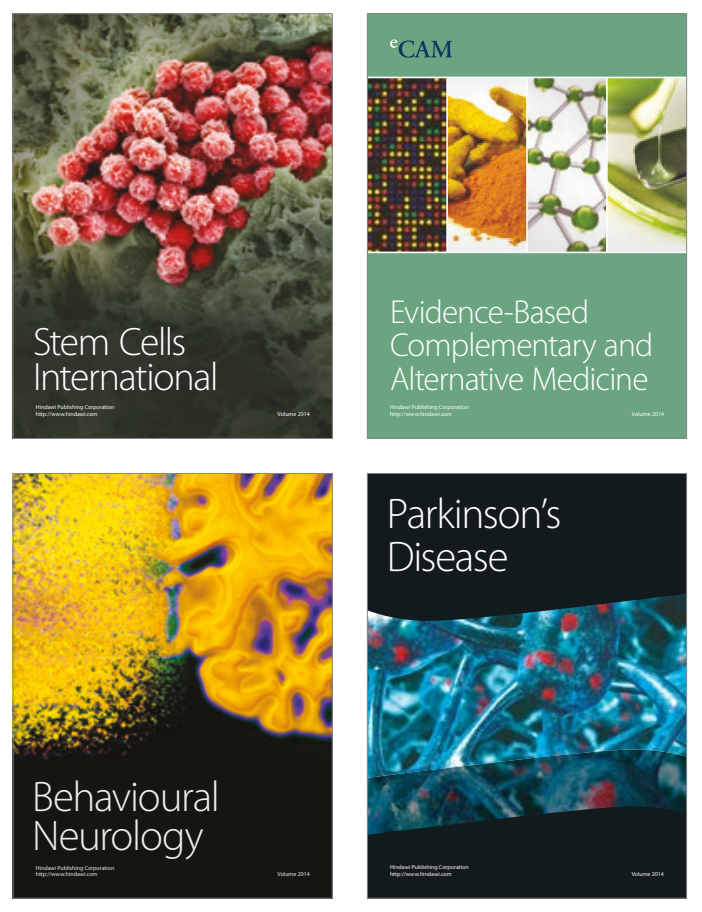
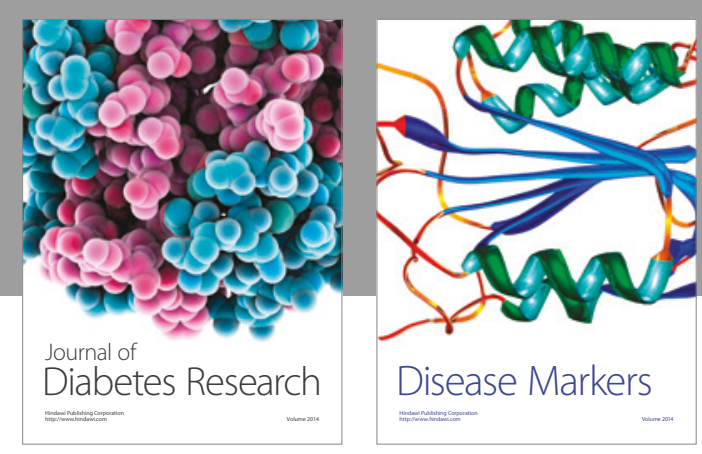

Disease Markers
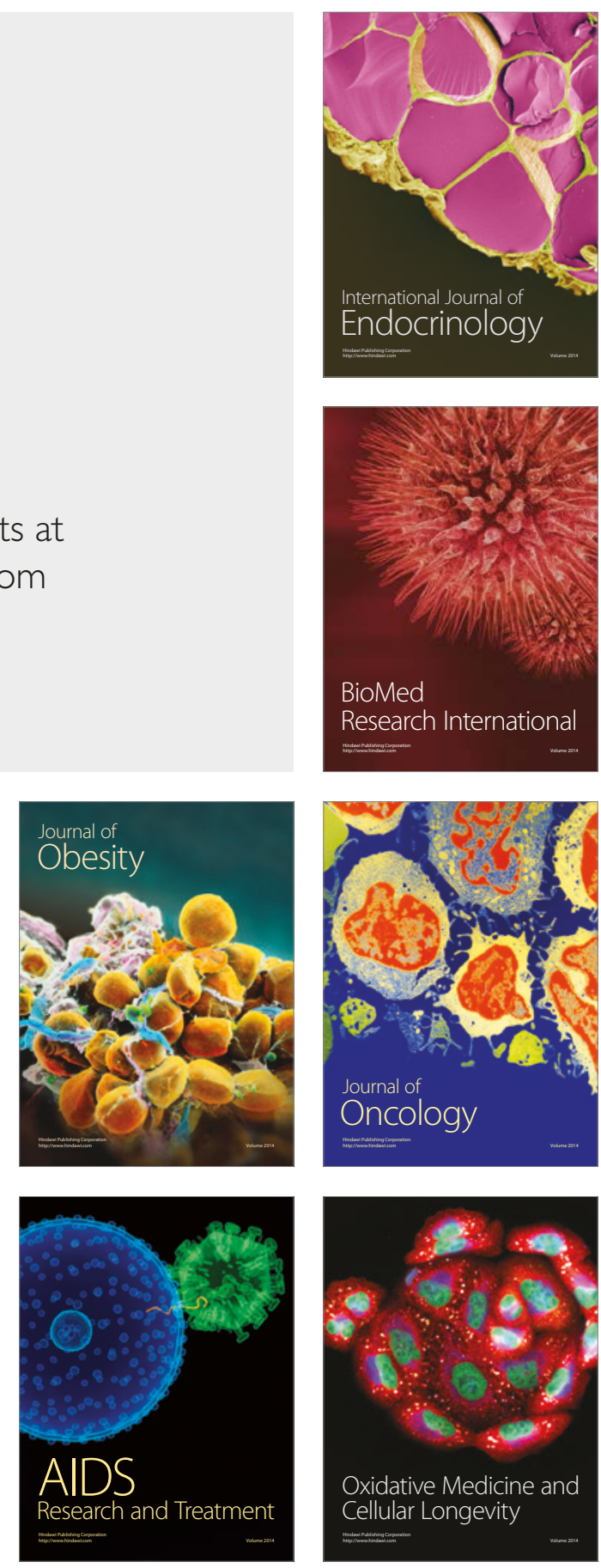